\title{
Extented measures for controlling an outbreak of VIM-1 producing imipenem-resistant Klebsiella pneumoniae in a liver transplant centre in France, 2003-2004
}

\author{
N Kassis-Chikhani (najiby.kassis-chikhani@pbr.aphp.fr) ${ }^{1,2}$, F Saliba ${ }^{3}$, A Carbonne $^{4}$, S Neuville ${ }^{5}$, D Decre Ca,7, $^{6,}$ C Sengelin ${ }^{1,2}$, C \\ Guerin $^{1}$, N Gastiaburu3 , A Lavigne-Kriaa3, C Boutelier ${ }^{1}$, G Arlet ${ }^{7,8,9}$, D Samuel ${ }^{3,10}$, D Castaing ${ }^{3,10}$, E Dussaix ${ }^{2,10}$, V Jarlier ${ }^{5,7,11}$ \\ 1. Assistance Publique-Hôpitaux de Paris, hospital Paul Brousse, Infection Control Unit, Villejuif, France \\ 2. Assistance Publique-Hôpitaux de Paris, hospital Paul Brousse, Microbiology Laboratory, Villejuif, France \\ 3. Assistance Publique-Hôpitaux de Paris, hospital Paul Brousse, Centre Hépato-Biliaire, Villejuif, France \\ 4. Centre de Coordination de la Lutte contre les Infections Nosocomiales (CCLIN, Coordinating centre in the fight against \\ nosocomial infections) Paris-Nord, France \\ 5. Assistance Publique-Hôpitaux de Paris, Central Infection Control Team, Paris, France \\ 6. Assistance Publique-Hôpitaux de Paris, hospital Saint-Antoine, Bacteriology, Paris, France \\ 7. Université Pierre et Marie Curie, Paris 6, France \\ 8. ER8 Antibiotiques et Flore digestive, Université Paris 6, Paris, France \\ 9. Assistance Publique-Hôpitaux de Paris, hospital Tenon, Bacteriology, Paris, France \\ 10. Université Paris-Sud, UMR 785, Villejuif, France \\ 11. Assistance Publique-Hôpitaux de Paris, hospital Pitié-Salpétrière, Paris, France
}

Kassis-Chikhani N, Saliba F, Carbonne A, Neuville S, Decre D, Sengelin C, Guerin C, Gastiaburu N, Lavigne-Kriaa A, Boutelier C, Arlet G, Samuel D, Castaing D, Dussaix E, Jarlier V. Extented measures for controlling an outbreak of VIM-1 producing imipenem-resistant Klebsiella pneumoniae in a liver transplant centre in France, 2003-2004. Euro Surveill. 2010;15(46):pii=19713. Available online: http://www.eurosurveillance.org/ViewArticle.aspx?Articleld=19713

We report the successful control of an outbreak caused by imipenem-resistant VIM-1-producing Klebsiella pneumoniae (IR-Kp) in France. This outbreak occurred in a care centre for abdominal surgery that includes a 15-bed liver intensive care unit and performs more than 130 liver transplantations per year. The index case was a patient with acute liver failure transferred from a hospital in Greece for urgent liver transplantation who was carrying IR-Kp at admission as revealed by routine culture of a rectal swab. Infection control measures were undertaken and included contact isolation and promotion of hand hygiene with alcohol-based hand rub solution. Nevertheless, secondary IR-Kp cases were identified during the six following months from 3 December 2003 to 2 June 2004. From 2 June to 21 October, extended infection control measures were set up, such as cohorting IR-Kp carriers, contact patients and new patients in distinct sections with dedicated staff, limiting ward admission, and strict control of patient transfer. They led to a rapid control of the outbreak. The global attack rate of the IR-Kp outbreak was $2.5 \%, 13 \%$ in liver transplant patients and $0.4 \%$ in the other patients in the care centre ( $p<0.005)$. Systematic screening for IR-Kp of all patients admitted to the care centre is still maintained to date and no secondary IR-Kp case has been detected since 2 June 2004 .

\section{Introduction}

Klebsiella pneumoniae has been a prominent cause of nosocomial infections and outbreaks, particularly in intensive care units. Metallo-beta-lactamases (MBLs) hydrolyse all beta-lactam antibiotics including carbapenems (except aztreonam) and are reported increasingly in Enterobacteriaceae. Among MBLs, the first member of the VIM-family of enzymes, VIM-1, was identified in a clinical isolate of Pseudomonas aeruginosa in Verona, Italy [1]. During the last decade, VIMtype MBLs have spread in Enterobacteriaceae [2-10] and outbreaks of such strains have been reported in Greece [11] and Italy [12]. Klebsiella pneumoniae carbapenemase (KPC) is one of the most prevalent carbapenemases in Enterobacteriaceae especially in Asia, Israel, southern Europe, the United Kingdom (UK), and the United States (US) [13]. In 2009, a novel MBL named NDM-1 (New Delhi metallo-beta-lactamase) was identified by Yong $\mathrm{D}$ et al. in K. pneumoniae and Escherichia coli isolates recovered from a Swedish patient transferred from India to a hospital in Sweden [14]. A recent study reported NDM-1 MBLs in various Enterobacteriaceae in the UK [15]. Many of the NDM1-positive patients had travelled in India or Pakistan in the year preceding their infection or had links with these countries [15]. Population mobility is known to be a major factor in the spread of multidrug-resistant organisms [16]. Prevention of the spread of carbapenemases, especially into northern and western European countries where these enzymes are not yet endemic, is vital. The European Union is facing the threat of multiple outbreaks involving carbapenemase-producing Enterobacteriaceae and thus needs to establish guidelines to control such outbreaks rapidly and efficiently.

We report on the first control of an outbreak involving a single strain of VIM-1-producing $K$. pneumoniae that occurred in 2004 at Paul Brousse hospital, a 716-bed 
tertiary-care teaching hospital of Assistance PubliqueHôpitaux de Paris (AP-HP), the largest public health institution in France with 23,000 beds. The outbreak occurred in the abdominal surgery care centre that comprises 81 single bedrooms including 15 beds on the first floor dedicated to intensive care and an acute care facility of 66 beds located on the third and fourth floors of the building. The intensive care unit admits more than 800 patients per year. The abdominal surgery care centre performs more than 130 liver transplantations per year, $15 \%$ of them in patients from foreign countries, and 200 hepatectomies.

We have previously described the bacteriological characteristics of the strain involved in this outbreak [17].
We describe here the characteristics of the IR-Kp cases and the specific measures that led to the control of the outbreak.

\section{Outbreak description}

The index case (Case 1) was a patient with acute fulminant hepatic failure admitted on 2 December 2003 to the intensive care unit for an urgent liver transplantation. He was transferred from Athens, Greece, where he had been hospitalised for an acute hepatitis due to hepatitis B virus infection. It was the first time that an IR-Kp has been identified in our hospital, since systematic screening for extended spectrum beta-lactamase (ESBL)-producing Enterobacteriaceae was introduced in 2002. We learnt later that the Greek hospital this

\section{TABLE 1}

Clinical characteristics of patients colonised or infected with imipenem-resistant Klebsiella pneumoniae in an abdominal surgery care centre, France, 2003-2004 ( $n=8)$

\begin{tabular}{|c|c|c|c|c|c|c|c|c|}
\hline Case & $\begin{array}{c}\text { Age } \\
\text { (years) }\end{array}$ & $\begin{array}{c}\text { Date of } \\
\text { admission }\end{array}$ & Clinical events & $\begin{array}{c}\text { First isolate: } \\
\text { site }\end{array}$ & $\begin{array}{c}\text { Interval between } \\
\text { admission and } \\
\text { IR-Kp isolation } \\
\text { (days) }\end{array}$ & Antibiotic treatment & Outcome & $\begin{array}{c}\text { Suspected place } \\
\text { of acquisition }\end{array}$ \\
\hline 1 & $\begin{array}{l}\text { in their } \\
205\end{array}$ & $\begin{array}{c}\text { December } \\
2003\end{array}$ & $\begin{array}{c}\text { Liver } \\
\text { transplantation }\end{array}$ & rectal swab & 0 & No treatment & Discharged & $\begin{array}{c}\text { Index case } \\
\text { transferred from } \\
\text { Greece }\end{array}$ \\
\hline 2 & $\begin{array}{l}\text { in their } \\
505\end{array}$ & $\begin{array}{l}\text { December } \\
2004\end{array}$ & $\begin{array}{c}\text { Liver } \\
\text { transplantation }\end{array}$ & $\begin{array}{l}\text { blood } \\
\text { culture }\end{array}$ & 13 & No treatment & Discharged & $\begin{array}{l}\text { Acute care } \\
\text { facility }\end{array}$ \\
\hline 3 & $\begin{array}{l}\text { in their } \\
60 \mathrm{~s}\end{array}$ & $\begin{array}{l}\text { September } \\
2003\end{array}$ & $\begin{array}{c}\text { Liver } \\
\text { transplantation }\end{array}$ & $\begin{array}{l}\text { tracheal } \\
\text { fluid }\end{array}$ & 175 & $\begin{array}{l}\text { Piperacillin/ } \\
\text { tazobactama } \\
\text { Ciprofloxacin }{ }^{a}\end{array}$ & $\begin{array}{l}\text { Deceased } \\
\text { (due to IR-Kp } \\
\text { infection) }\end{array}$ & $\begin{array}{l}\text { Acute care } \\
\text { facility }\end{array}$ \\
\hline 4 & $\begin{array}{c}\text { in their } \\
605\end{array}$ & $\begin{array}{c}\text { February } \\
2004\end{array}$ & $\begin{array}{c}\text { Liver } \\
\text { transplantation }\end{array}$ & urine culture & 48 & $\begin{array}{c}\text { No treatment } \\
\text { (asymptomatic) }\end{array}$ & Deceased & $\begin{array}{c}\text { Intensive care } \\
\text { unit }\end{array}$ \\
\hline 5 & $\begin{array}{c}\text { in their } \\
70 \mathrm{~s}\end{array}$ & April 2004 & Liver cirrhosis & urine culture & 31 & $\begin{array}{c}\text { No treatment } \\
\text { (asymptomatic) }\end{array}$ & Deceased & $\begin{array}{c}\text { Intensive care } \\
\text { unit }\end{array}$ \\
\hline 6 & $\begin{array}{l}\text { in their } \\
50 \mathrm{~s}\end{array}$ & $\begin{array}{l}\text { January } \\
2004\end{array}$ & $\begin{array}{c}\text { Liver } \\
\text { transplantation }\end{array}$ & $\begin{array}{l}\text { blood } \\
\text { culture }\end{array}$ & 173 & Colistin & $\begin{array}{c}\text { Deceased } \\
\text { (due to IR-Kp } \\
\text { infection) }\end{array}$ & $\begin{array}{c}\text { Intensive care } \\
\text { unit }\end{array}$ \\
\hline 7 & $\begin{array}{c}\text { in their } \\
505\end{array}$ & March 2004 & $\begin{array}{c}\text { Liver } \\
\text { transplantation }\end{array}$ & rectal swab & 101 & No treatment & Discharged & $\begin{array}{c}\text { Intensive care } \\
\text { unit }\end{array}$ \\
\hline 8 & $\begin{array}{c}\text { in their } \\
40 \mathrm{~s}\end{array}$ & $\begin{array}{c}\text { January } \\
2004\end{array}$ & $\begin{array}{c}\text { Liver } \\
\text { transplantation }\end{array}$ & rectal swab & 206 & No treatment & Discharged & $\begin{array}{c}\text { Acute care } \\
\text { facility }\end{array}$ \\
\hline
\end{tabular}

a Two antibiotics to which the stain was resistant. IR-Kp was identified post mortem.

\section{TABLE 2}

Organisation of distinct sections in intensive care unit and acute care facility during Period 2 of the control measures, abdominal surgery care centre, France, 2 June to 21 October 2004

\begin{tabular}{|c|c|c|}
\hline & \multicolumn{2}{|c|}{ Separation with plastic wall } \\
\hline \multirow[b]{2}{*}{$\begin{array}{l}\text { First floor } \\
\text { intensive care } \\
\text { unit }\end{array}$} & IR-Kp patients section & IR-Kp-free - long stay intensive care unit section \\
\hline & $\begin{array}{l}\text { IR-Kp patients who stayed in intensive care until } \\
\text { discharge } \\
\text { Number of beds }: 3\end{array}$ & $\begin{array}{c}\text { Patients requiring intensive care for an expected duration of } \\
\text { more than } 48 \text { hours } \\
\text { Number of beds }{ }^{\mathrm{a}}: 12\end{array}$ \\
\hline \multirow[b]{2}{*}{$\begin{array}{l}\text { Third floor } \\
\text { acute care facility }\end{array}$} & IR-Kp free patients non-intensive care unit section & IR-Kp-free - short stay intensive care unit section \\
\hline & $\begin{array}{l}\text { Patients directly admitted to the acute care facility } \\
\qquad \text { Number of beds }{ }^{\mathrm{a}}: 25\end{array}$ & $\begin{array}{c}\text { Patients having major surgery but requiring monitoring for less } \\
\text { than } 48 \text { hours } \\
\text { Number of beds }{ }^{\mathrm{a}}: 5\end{array}$ \\
\hline \multirow{2}{*}{$\begin{array}{l}\text { Fourth floor } \\
\text { acute care facility }\end{array}$} & \multicolumn{2}{|c|}{ Contact acute care section } \\
\hline & \multicolumn{2}{|c|}{$\begin{array}{l}\text { Patients hospitalised on the same floor and at the same time as an IR-Kp patient } \\
\text { Number of beds } \mathrm{s}^{\mathrm{a}}: 36\end{array}$} \\
\hline
\end{tabular}

IR-Kp: imipenem-resistant VIM-1-producing Klebsiella pneumoniae.

a Only single bedrooms. 
patient had been transferred from was at that time experiencing an outbreak with IR-Kp [8].

A secondary IR-Kp case was defined as a patient with IR-Kp isolated from any clinical sample (if infected) and/ or from a rectal swab (if colonised). In the context of this outbreak, five further cases of IR-Kp infection and two cases of IR-Kp colonisation occurred in our hospital. The characteristics of the IR-Kp cases are listed in
Table 1 . Six of the seven secondary cases had a liver transplantation and one had end-stage liver cirrhosis.

The interval between admission and the first IR-Kppositive specimen ranged between 13 and 206 days (median: 101 days). Considering only the seven cases who acquired IR-Kp in the abdominal surgery care centre (Table 1), patient age ranged between 46 and 69 years (median 62 years).

\section{FIGURE 1}

Synoptic curve of imipenem-resistant Klebsiella pneumoniae cases (infection and colonisation) in an abdominal surgery care centre, France, December 2003 to October $2004(\mathrm{n}=8)$

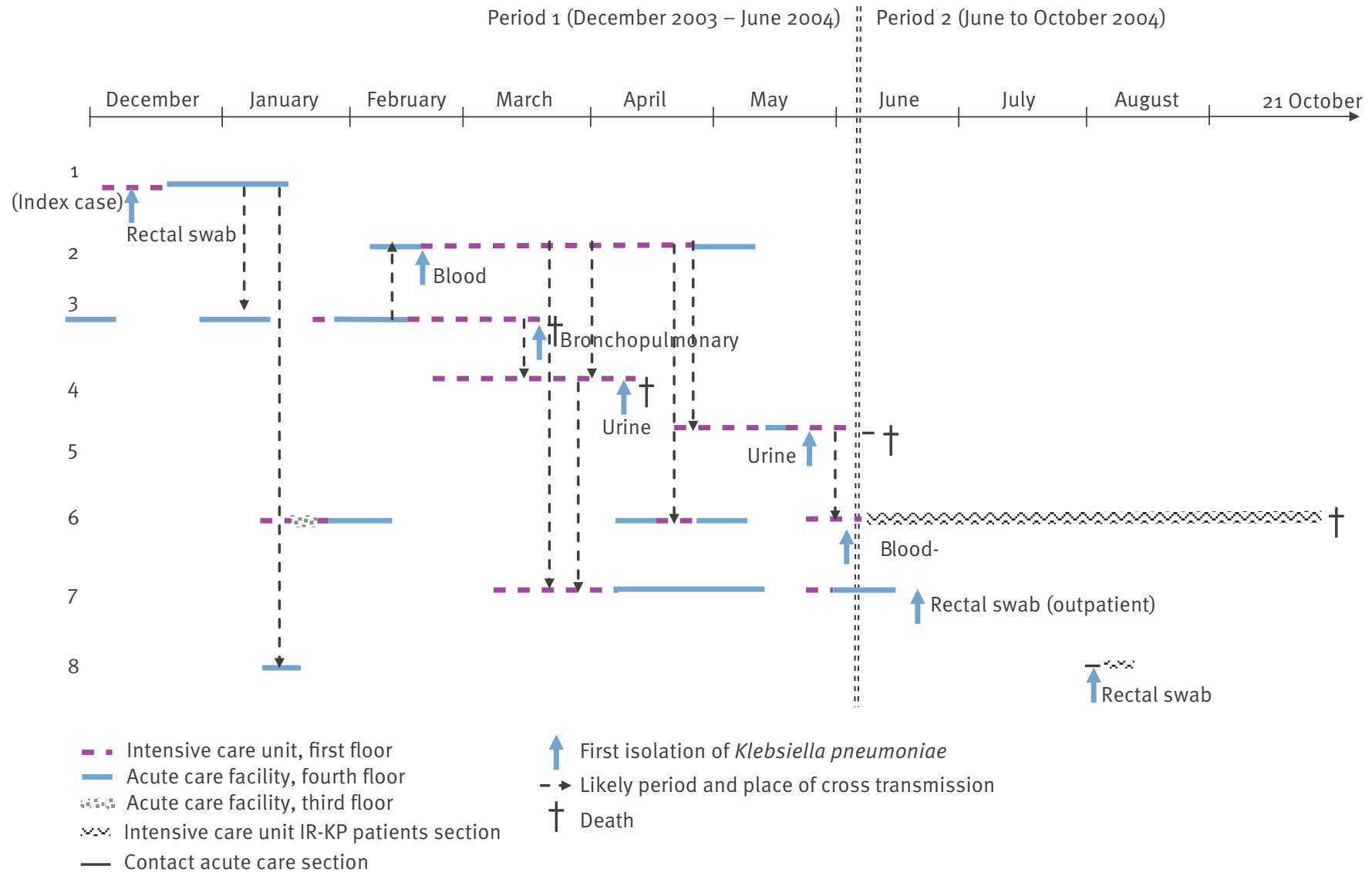

\section{FIGURE 2}

Patients screened in connection with an outbreak of imipenem-resistant Klebsiella pneumoniae in an abdominal surgery care centre, France, 2 December 2003 to 21 October 2004

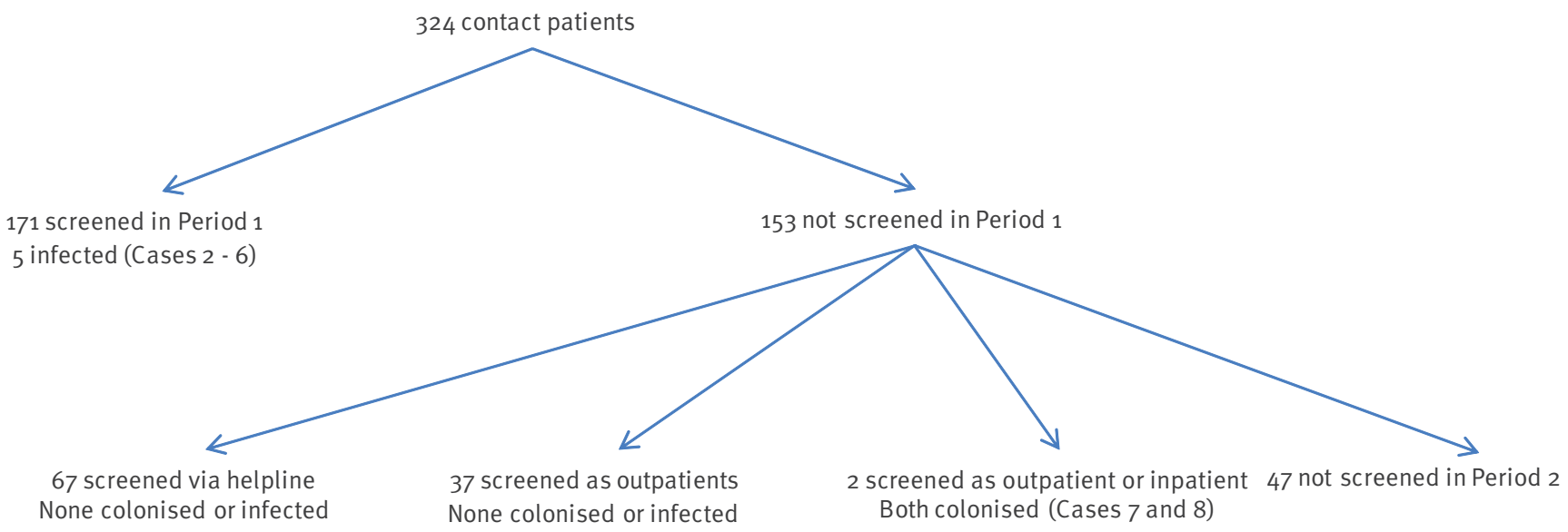




\section{Treatment and outcome}

IR-Kp was isolated from a rectal swab of the index case sampled on the day of admission to the intensive care unit. This case did not receive any antibiotic therapy during his stay and remained colonised until he was discharged in January 2004 and returned to Greece.

The five secondary IR-Kp cases (Cases 2 to 6) were treated as follows: Case 2 had a central venous catheter-related bloodstream infection that resolved after removal of the catheter, without antibiotic treatment. Case 3 received piperacillin/tazobactam and ciprofloxacin for bacteraemia (two antibiotics to which the strain was resistant, see chapter on Microbiological diagnostic) and died of Gram-negative septic shock, the IR-Kp having been identified only after the patient's death. Cases 4 and 5 had an asymptomatic urinary tract infection with IR-Kp and did not receive any antibiotic therapy. Case 6 had a liver abscess caused by IR-Kp and was treated with colistin. Four months after an apparent cure, the patient had a relapse and died deceased from IR-Kp bacteraemia associated with endstage liver failure.

The two secondary cases with IR-Kp colonisation (Cases 7 and 8) were not treated.

Cases 1, 2, 7 and 8 were discharged, while cases 3 to 6 died either in direct relation to their IR-Kp infection (Case 3 and 6) or from other reasons related to pathology. Interestingly, Cases 2 and 7 became IR-Kpnegative 15 months and two months, respectively, after initial diagnosis, whereas Case 8 was still carrying IR-Kp in July 2008, four years after initial diagnosis.

\section{Control measures}

\section{Period 1 (2 December 2003 to 2 June 2004)}

Immediately after identification of the index case, measures were implemented according to the French recommendations for controlling multidrug-resistant bacteria in hospital [18]: isolation of positive patients in a single bed room, barrier precautions (e.g. gowns and gloves for staff when entering the patient's room), hand disinfection with alcohol-based hand-rub solution before entering and after leaving the room, and environmental disinfection of the room [18]. Training of staff was organised to insure stringent application of these measures. All patients hospitalised in the intensive care unit were screened for IR-Kp once a week. This screening was maintained when these patients were transferred to the acute care facility.

Despite these measures, new IR-Kp carriers were identified in the intensive care unit during this period (see Table 1) which led to the implementation in June 2004 of extended infection control measures to stop cross-transmission.

\section{Period 2 (2 June to 21 October 2004)}

The additional control measures were implemented with the help of the central infection control team of AP-HP. Firstly, we defined five distinct sections in the intensive care unit and acute care facility (Table 2) in order to separate IR-Kp-carrying patients, contact patients and newly admitted patients who were neither IR-Kp-carrying nor contact patients (IR-Kp-free patients). Contact patients were defined as patients who had stayed on the same floor at the same time as an IR-Kp patient (even if this time was less than 24 hours) before the implementation of the reinforced control measures on 2 June 2004 .

Secondly, we thoroughly modified the organisation of care in the abdominal surgery care centre. Nursing staff was assigned exclusively to one of the five sections. Admissions of new patients were limited to emergencies and liver transplants. In order to prevent spread of the outbreak to other care centres, transfers were allowed only for IR-Kp-free patients. Transfer of IR-Kp patients within our hospital or to another hospital was allowed only for specific investigations (e.g. computed axial tomography or magnetic resonance imaging) and organised by the local infection control team to ensure that barrier precautions were respected. If patients carrying IR-Kp were readmitted after discharge, they were directly hospitalised in the 'IR-Kp patients section'. If they presented as outpatients for consultation, the local infection control team was informed, control measures were taken and the patients were screened again for IR-Kp. Daily meetings between the medical and nursing staff at the abdominal surgery care centre and the local infection control team helped to strengthen compliance with the control measures. The local infection control team inspected the implementation of the measures at the bedside every day.

Thirdly, it was recommended that clinicians should optimise and restrict the use of antibiotics, in particular of imipenem/cilastatin. An information letter explaining the measures was posted at the information desk of each floor of the abdominal surgery care centre, given to all patients hospitalised in the centre and to their families and also distributed to the other units of the hospital. IR-Kp patients were informed of their status and received instructions when discharged: they were invited to come back preferentially to our hospital in case of medical problem and, if hospitalised in another hospital, to inform the medical staff there about their IR-Kp status.

Finally, the French health authorities organised a screening campaign targeting the contact patients discharged from the abdominal surgery care centre during Period 1 who had not been screened. They were invited to call a free helpline where two senior physicians and a resident physician were available from 26 July to 6 August 2004 and explained how to be screened either in our hospital or, alternatively, in any laboratory of the patients' choice. In the latter case, the procedure to detect IR-Kp was mailed to the chosen laboratory and the result was sent to our hospital. 
In June 2004, an alert describing the antibiotic resistance pattern of the IR-Kp was posted on the website of the French institute of public health surveillance (Institut de Veille Sanitaire), and sent to the Early Warning Response System of the European health authorities.

The extended measures were maintained until the end of October 2004 when the last IR-Kp patient was discharged from the abdominal surgery care centre. This patient was transferred to the infectious disease unit located in a separated building of the hospital, where the same control measures were taken (i.e. establishing a special unit with dedicated nursing staff) until the patient died on 15 December. Screening of contact patients for IR-Kp was maintained at each re-admission of in- or outpatients to our hospital until the end of 2005. This measure was stopped because the number of contact patients coming back to the abdominal surgery care centre had decreased and all had had at least three (on average 10) successive negative screenings.

\section{Microbiological diagnostic}

Rectal swabs were plated on Drigalski agar containing $0.5 \mathrm{mg} / \mathrm{L}$ of cefotaxime, MacConkey agar containing 2 $\mathrm{mg} / \mathrm{L}$ of ceftazidime. In Period 2 we added Drigalski agar plates containing $4 \mathrm{mg} / \mathrm{L}$ of imipenem until the end of 2005. Antibiotic susceptibility testing, including for imipenem, was performed by agar disk diffusion test according to the recommendations from the French Society for Microbiology [19] A disk synergy test between imipenem and EDTA was used to detect $M B L$ production. The presence of the ESBL in MBLproducing strains was detected by a synergy test between ceftazidime or cefepime and clavulanic acid by adding $4 \mu \mathrm{l}$ of $0.5 \mathrm{M}$ EDTA pH 8 on the disk of clavulanic acid [17]. Polymerase chain reaction (PCR) and pulsed-field gel electrophoresis (PFGE) were used to type IR-Kp strains [17].

All IR-Kp strains shared closely related resistance patterns: a high level of resistance to beta-lactams including imipenem (minimum inhibitory concentration (MIC) $\geq 32 \mathrm{mg} / \mathrm{L}$ ), aminoglycosides (except gentamicin), fluoroquinolones and co-trimoxazole; a low level of resistance to gentamicin $(\mathrm{MIC}=8 \mathrm{mg} / \mathrm{L})$ and susceptibility to colistin [17]. All strains carried the $b l a_{\mathrm{vIM}}$ and bla $a_{\text {SHV-5 }}$ genes. The isolates from our eight patients had the same restriction pattern, identical to the strain $\mathrm{K}_{5}$ reported in teaching hospitals in Greece $[8,17]$. The outbreak was consequently ascribed to the spread of a single strain. This strain has not been isolated in our hospital again since the last case of this outbreak was discharged.

\section{Epidemiological analysis}

Rates of IR-Kp infection or colonisation were calculated for all patients admitted between December 2003 (month of the first case) and June 2004 (month of the last case). Rates were calculated separately for those cases who had a liver transplantation and those who stayed in the intensive care unit. Fischer's exact test was used to compare categorical variables and p<0.05 was considered significant.

\section{Period 1}

During Period 1, 325 patients stayed in the intensive care unit (237 of them stayed also in the acute care facility) and 375 further patients were admitted only to the acute care facility (total=700 patients). Five secondary IR-Kp cases (Cases 2 to 6 ) were detected: all had IR-Kp infections (two bacteraemias, one bronchopulmonary infection, two urinary tract infections) (Table 1). Analysis of the synoptic curve of the patients' charts suggested that three of them (Cases 4, 5 and 6) acquired the infection in the intensive care unit, and the two others (Cases 2 and 3 ) in the acute care facility on the fourth floor before surgery (Figure 1).

Based on the analysis of the stays of the index case and the above secondary cases, 324 of the 700 patients admitted during this period were retrospectively defined as contact patients and had been exposed to IR-Kp. Of those, 171 were screened during their stay in abdominal surgery care centre. The remaining 153 contact patients, discharged during Period 1, were not screened in the abdominal surgery care centre, predominantly due to the short duration of their stay, and were the target of the screening campaign organised in Period 2 (see below).

\section{Period 2}

During the screening campaign (26 July to 6 August 2004) 75 of the 153 contact patients who had not been screened in Period 1 called the helpline for information and 67 subsequently accepted to be screened ( 54 in our hospital and 13 in another facility). A further 37 patients did not call the helpline during this campaign but were screened after the helpline had been closed when visiting our hospital as outpatients. Overall, 104 of the 153 patients who were not screened during Period 1 were screened in Period 2. None of them were found to carry IR-Kp.

In addition, two secondary IR-Kp cases (Cases 7 and 8) were identified in June and August 2004 after the extended infection control measures. Case 7 was a contact patient who had stayed in the intensive care unit from 8 March to 3 June, at the same time as Cases 2, 3 and 4. After discharge, this patient visited the abdominal surgery care centre as an outpatient on 17 June. According to the measures in force at this time, this patient was screened and identified as a IR-Kp carrier. Case 8 , who had stayed in the acute care facility for four days in January 2004, at the same time as the index case, was re-admitted on 28 July on the fourth floor in the 'contact acute care patients section' where all patients were IR-Kp-negative (Figure 1). This patient was screened and transferred to the 'IR-Kp patients section' after IR-Kp was detected in the rectal swab. Based on the synoptic curve (Figure 1), Cases 7 and 8 
are most likely to have acquired IR-Kp during Period 1. They did not develop IR-Kp infection.

\section{Attack rate}

A total of 277 of the 324 contact patients ( $85 \%$ ) were screened (Figure 2). The global attack rate of secondary IR-Kp cases $(n=7)$ among the screened contact patients $(n=277)$ was $2.5 \%$.

The attack rate of secondary cases was significantly higher among patients with liver transplant (six of 45 patients; $13 \%$ ) as compared to screened patients without liver transplant (one of 230 patients; $0.4 \%$ ) $(p=0.0001)$. Although all secondary cases stayed at least some days in the intensive care unit, the likely place of IR-Kp acquisition for three of them was the acute care facility. Which hospital unit the patient stayed in was not a risk factor for acquisition of IR-Kp, as the attack rate was $1.2 \%$ in patients staying in the intensive care unit (four of 325 patients) and $0.6 \%$ in other patients (three of 375 patients) $(p=0.4)$

\section{Cost of the screening campaign}

The estimated cost of the screening campaign organised in period two (personnel costs for two seniors physicians and one resident physician maintained on duty, telephone bills, mailing costs, sampling and cultures) was EUR 18,830, i.e. a mean of EUR 190 per screened patient. The annual cost of the routine weekly screening for ESBL- or carbapenemase-producing Enterobacteriaceae that has been maintained up to now for the entire abdominal surgery care centre $(81$ beds) is approximately EUR 60,000.

\section{Discussion}

The emergence and spread of carbapenem-resistant Enterobacteriaceae due to $\mathrm{MBL}$ is an increasing international health problem. In Europe, the proportion of K. pneumoniae strains resistant to imipenem (IR-Kp) that are isolated from blood cultures is far below $5 \%$ in most countries but had in the year 2007 already reached a rate of $22 \%$ in Israel and $42 \%$ in Greece. In France, the incidence is still very low ( $10.1 \%)$ and the very few identified cases are in relation with patients transferred from foreign countries [20].

We describe here the epidemiological characteristics and control of the first outbreak of MBL-producing K. pneumoniae that occurred in France, after the admission of a patient transferred from a hospital in Greece, where these bacteria are common [8]. To our knowledge, it is the first report on the control of an IR-Kp outbreak in a country with a low rate of these bacteria.

The national measures for controlling cross-transmission of multidrug-resistant bacteria in hospital [18], designed mainly for meticillin-resistant Staphylococcus aureus, were implemented during the first six months of the outbreak (Period 1) but were insufficient to achieve control, as five secondary cases occurred during that period. After implementation of the extended infection control measures (Period 2), the only two secondary cases identified were in fact, the consequence of acquisition during Period 1. The extended measures were mainly based on (i) separating IR-Kp patients, contact patients and new patients in distinct sections of the hospital, each with dedicated staff, in order to minimise cross-transmission, (ii) stopping transfer of IR-Kp patients to other units or hospitals to block the extension of the outbreak and (iii) careful identification, screening and follow up of the contact patients. The outbreak was most likely due to cross-transmission by the staff since all the patients in abdominal surgery care centre facility are placed in single bedrooms, particularly in intensive care unit. Successive attempts failed to detect the epidemic strain in environmental samples (data not shown).

The present study was not a randomised controlled trial assessing causality between intervention and outcome. Indeed, the rapid spread of IR-Kp in our hospital triggered rapid and strong action to control the outbreak, making a randomised intervention impossible. However, the fact that the strength and nature of the implemented measures differed markedly during Periods 1 and 2 as well as the length of the followup (six years) suggest a causal association between reinforced measures and the control of the outbreak. Causes other than the intervention (e.g. regression to the mean or maturation effect) could have been involved in the decrease in IR-Kp cases [21]. However, spontaneous cessation of IR-Kp outbreaks was not observed in Greece, Israel or the New York City area, where IR-Kp are endemic [8,22-24]. In one setting the incidence of endemic IR-Kp was partially reduced by implementing strict infection control measures comparable to our control programme, whereas contact isolation alone was unsuccessful [25]. Similar measures have also been implemented successfully to control the emergence of vancomycin-resistant enterococci (VRE) [26-28] and are now recommended for VRE outbreaks in France [29] and in the Netherlands [25]. These measures, proposed by the central infection control team of AP-HP, are more stringent than those proposed by the US Centers for Disease Control and Prevention [30].

We faced some difficulties in the implementation of reinforced infection control measures. Defining distinct sections in the hospital to separate IR-Kp carriers, contact patients and IR-Kp-free patients required a strong involvement of hospital managers and the support of the central infection control team of the AP-HP institution. Dedicating teams of nurses to each of these sections was a difficult challenge. Assigning the re-admitted contact patients to the adequate sections required careful examination of medical records. Reinforcing screening procedures increased the workload markedly and required a reorganisation of the laboratory. Maintaining the activity of liver transplantation was made possible by referring part of the patients who did not require transplantation to other care centres. Careful and clear information of patients and staff while avoiding stress and panic required psychological tact. 
Although extended measures such as those applied in our setting are difficult to implement and maintain for a long period of time, we believe that they are adequate to control outbreaks of emerging multiresistant organisms, particularly in countries where the incidence is very low $[25,31,32]$. Recent recommendations advocate implementing similar measures for the sporadic occurrence of IR-Kp [29]. The speed and strength of the intervention is likely to be crucial in limiting the size and duration of IR-Kp outbreaks.

The present study also suggests that pre-emptive isolation of patients at risk of carrying multidrug-resistant strains (i.e. resistant to VIM, KPC, NDM-1), particularly patients transferred from countries where these organisms are endemic, could help to prevent outbreaks. This measure should be combined with a preparedness plan to facilitate urgent and rapid action whenever a first case is detected [31].

\section{Acknowledgements}

The authors are grateful to Professor Vatopoulos (University of Athens) for providing IR-Kp strains, all staff at the Centre Hépato-Biliaire, the Infectious Disease Department, and the bacteriology laboratory, and Bruno Coignard at InVS. We also thank the hospital administration for their support.

\section{References}

1. Lauretti L, Riccio ML, Mazzariol A, Cornaglia G, Amicosante G, Fontana $\mathrm{R}$ et al. Cloning and characterization of blaVIM, a new integron-borne metallo- $\beta$-lactamase gene from Pseudomonas aeruginosa clinical isolate. Antimicrob Agents Chemother. 1999;43(7): 1584-90.

2. Jeong SH, Lee K, Chong Y, Yum JH, Lee SH, Choi HJ, et al. Characterization of a new integron containing VIM-2, a metallo$\beta$-lactamase gene cassette, in a clinical isolate of Enterobacter cloacae. J Antimicrob Chemother. 2003;51(2):397-400.

3. Scoulica EV, Neonakis IK, Gikas AI, Tselentis YJ et al. Spread of blaVIM-producing E. coli in a university hospital in Greece. Genetic analysis of the integron carrying the blaVIM-1 metallo$\beta$-lactamase gene. Diag Microbiol Infect Dis. 2004;48:167-72.

4. Conceicao T, Brizio A, Duarte A, Barros R, et al. First isolation of bla(VIM-2) in Klebsiella oxytoca clinical isolates from Portugal. Antimicrob Agents Chemother. 2005;49(1): 476.

5. Yan JJ, Ko WC, Chuang CL, Wu JJ. Metallo-beta-lactamaseproducing Enterobacteriaceae isolates in a university hospital in Taiwan: prevalence of IMP-8 in Enterobacter cloacae and first identification of VIM-2 in Citrobacter freundii. J Antimicrob Agents Chemother. 2002;50(4): 503-11.

6. Yum HY, Yong D, Kim HS, Chong Y. A new integron carrying VIM2 metallo- $\beta$-lactamase gene cassette in a Serratia marcescens. Diagn Microbiol Infect Dis. 2002;42(3): 217-8.

7. Miriagou V, Tzelepi E, Gianneli D, Tzouvelekis LS. Escherichia coli with a self-transferable, multiresistant plasmid coding for metallo-beta-lactamase VIM-1. Antimicrob Agent Chemother. 2003;47(1): 395-7.

8. Giakkoupi P, Xanthaki A, Kanelopoulou M, Vlahaki A, Miriagou V, Kontou S et al. VIM-1 metallo-beta-lactamase-producing Klebsiella pneumoniae strains in Greek hospitals. J Clin Microbiol. 2003; 41(8): 3893-6.

9. Galani I, Souli M, Chryssouli Z et al. First identification of an Escherichia coli clinical isolate producing both metallo-betalactamase VIM-2 and extended-spectrum $\beta$-lactamase IBC-1. Clin Microbiol Infect. 2004;10(8): 757-60.

10. Luzzaro F, Docquier JD, Colinon C et al. Emergence in Klebsiella pneumoniae and Enterobacter cloacae clinical isolates of the VIM-4 metallo-beta-lactamase encoded by a conjugative plasmid. Antimicrob Agent Chemother. 2004;48(2): 648-50.

11. Tsakris A, Pournaras S, Woodford N, Palepou MF, Babini GS, Douboyas J, et al. Outbreak of infections caused by Pseudomonas aeruginosa producing VIM-1 carbapenemase in Greece. J Clin Microbiol. 2000;38(3):1290-2.
12. Cornaglia G, Mazzariol A, Lauretti L, Rossolini GM, Fontana R. Hospital outbreak of carbapenem-resistant Pseudomonas aeruginosa producing VIM-1, a novel transferable metallobeta-lactamase. Clin Infect Dis. 2000;31(5):1119-25

13. Nordmann P, Cuzon G, Naas T. The real threat of Klebsiella pneumoniae carbapenemase-producing bacteria. Lancet Infect Dis. 2009; 9(4):228-36. Review.

14. Yong D, Toleman MA, Giske CG, Cho HS, Sundman K, Lee K et al. Characterization of a new metallo-beta-lactamase gene, bla(NDM-1), and a novel erythromycin esterase gene carried on a unique genetic structure in Klebsiella pneumoniae sequence type 14 from India. Antimicrob Agents Chemother. 2009; 53(12):5046-54.

15. Kumarasamy KK, Toleman MA, Walsh TR, Bagaria J, Butt F, Balakrishnan $\mathrm{R}$ et al. Emergence of a new antibiotic resistance mechanism in India, Pakistan, and the UK: a molecular, biological, and epidemiological study. Lancet Infect Dis. 2010;10 (9):597-602.

16. MacPherson DW, Gushulak BD, Baine WB, Bala S, Gubbins PO, Holtom $P$ et al. Population mobility, globalization, and antimicrobial drug resistance. Emerg Infect Dis. 2009;15(11):1727-32.

17. Kassis-Chikhani N, Decré D, Gautier V Burghoffer B, Saliba F, Mathieu D et al. First outbreak of multidrug-resistant Klebsiella pneumoniae carrying blaVIM-1 and blaSHV- 5 in a French university hospital. J Antimicrob Chemother. 2006;57(1):142-5.

18. Comité Technique national des Infections Nosocomiales (CTIN): Maîtrise de la diffusion des bactéries multirésistantes aux antibiotiques. Recommandations pour les établissements de santé. Ministère de l'Emploi et de la Solidarité, Secrétariat d'Etat à la Santé et à l'Action sociale. 1999.

19. Comité de l'antibiogramme de la Société Française de Microbiologie (SFM). Recommandations 2010; page 4. Available from: http://www.sfm.asso.fr/publi/general.php?pa=1

20. European Centre for Disease Prevention and Control (ECDC). Annual epidemiological report on communicable diseases in Europe 2008. Report on the state of communicable diseases in the EU and EEA/EFTA countries, p 173. Stockholm; 2008. Available from: http://ecdc.europa.eu/en/publications/ Publications/0812_SUR_Annual_Epidemiological_ Report_2008.pdf.

21. Harris AD, Bradham DD, Baumgarten M, Zuckerman IH, Fink JC and Perencevich EN. The use and interpretation of quasiexperimental studies in infectious diseases. Clin Infect Dis. 2004;38(11):1586-91

22. Vatopoulos A. High rates of metallo-beta-lactamaseproducing Klebsiella pneumoniae in Greece - a review of the current evidence. Euro Surveill. 2008;13(4):pii=8023. Available from: http://www.eurosurveillance.org/ViewArticle. aspx?Articleld $=8023$

23. Cagnacci S, Gualco L, Roveta S Mannelli S, Borgianni L, Docquier JD et al. Bloodstream infections caused by multidrugresistant Klebsiella pneumoniae producing the carbapenemhydrolysing VIM-1 metallo-beta-lactamase: first Italian outbreak. J Antimicrob Chemother. 2008;61(2):296-300

24. Bratu S, Landman D, Haag R, Recco R, Eramo A, Alam M, et al. Rapid spread of carbapenem-resistant Klebsiella pneumoniae in New York City. Arch Intern Med. 2005;165(12):1430-35.

25. Kochar S, Sheard T, Sharma R, Hui A, Tolentino E, Allen G et al. Success of an infection control program to reduce the spread of carbapenem-resistant Klebsiella pneumoniae. Infect Control Hosp Epidemiol. 2009;30(5):447-52.

26. Lucet JC, Armand-Lefevre L, Laurichesse JJ, Macrez A, Papy $E$, Ruimy $R$ et al. Rapid control of an outbreak of vancomycinresistant enterococci in a French university hospital. J.Hosp Infect. 2007; 67(1):42-8.

27. Ridwan B, Mascini E, van Der Reijden N, Verhoef J and Bonten $\mathrm{M}$. What action should be taken to prevent spread of vancomycin resistant enterococci in European hospitals? BMJ. 2002;324(7338):666-8

28. Kurup A, Chlebicki MP, Ling ML, Koh, TH, Tan KY, Lee LC, et al. Control of a hospital-wide vancomycin-resistant Enterococci outbreak. Am J Infect Control. 2008;36(3):206-11

29. Prévention de l'émergence des épidémies d'entérocoques résistants à la vancomycine dans les établissements de santé. Fiche technique opérationnelle. Décembre 2006.

30. Centers for Disease Control and Prevention (CDC). Guidance for control of infections with carbapenem-resistant or carbapenemase-producing Enterobacteriaceae in acute care facilities. Morb Mortal Wkly Rep. 2009 Mar 20;58(10):256-60.

31. Carmeli Y, Akova M, Cornaglia G, Daikos GL, Garau J, Harbarth $S$ et al. Controlling the spread of carbapenemase-producing Gram-negatives: therapeutic approach and infection control. Clin Microbiol Infect. 2010;16(2):102-11.

32. Schwaber MJ, Carmeli Y. Carbapenem-resistantEnterobacteriaceae: A potential threat. JAMA. 2008;300(24):2911-3 